\title{
Accuracy of oxygen delivery by liquid oxygen canisters
}

\author{
M.J. Kampelmacher*, P.B. Cornelisse**, G.P.J. Alsbach+, R.G. van Kesteren*, \\ C.F. Melissant++, J.M.C. Douze*, J-W.J. Lammers++
}

Accuracy of oxygen delivery by liquid oxygen canisters. M.J. Kampelmacher, P.B. Cornelisse, G.P.J. Alsbach, R.G. van Kesteren, C.F. Melissant, J.M.C. Douze, J-W.J. Lammers. COERS Journals Ltd 1998.

ABSTRACT: The oxygen flow rate delivered by liquid oxygen canisters may be less than intended, owing to inaccuracies of the set flow rates and/or as a result of the outflow resistance caused by the humidifier, oxygen tubing, delivery or conserving device. The aim of this study was to investigate the accuracy of oxygen delivery by liquid oxygen canisters at different flow rates and levels of outflow resistance.

Four stationary and 18 portable liquid oxygen canisters from three manufacturers were tested. All flows were measured using a Timemeter RT 200 Calibration Analyser. An adjustable obstruction was used to calculate the effect of the outflow resistance on the delivered flow rate.

The measured and set flow rates of both stationary and portable canisters were strongly correlated. Expressed as a percentage of the set flow rate, the measured flow rate of the canisters varied from 36-128\%, with the lowest values at flow rates $<1$ L.min-1. Sixty-two $(26 \%)$ of the measured flow rates differed Š $10 \%$ from the set flow rate. A difference of $0.5-1.0 \mathrm{~L} \cdot \mathrm{min}^{-1}$ occurred in $16(7 \%)$ of the measurements, but only at set flow rates $>2 \mathrm{~L} \cdot \mathrm{min}^{-1}$. Irrespective of the set flow rate, the measured flow rate was hardly affected by the outflow resistance.

We conclude that the accuracy of oxygen delivery by liquid oxygen canisters depends on the inaccuracy of the set flow rates rather than on the outflow resistance, even at high flow rates. Although the differences between the measured and set flow rates were mostly small, they may have clinical significance, particularly in patients with chronic obstructive pulmonary disease. To prevent inaccuracy, monthly checks of the canisters by the oxygen provider at the patient's home are more important than yearly maintenance.

Eur Respir J 1998; 12: 204-207.
*Centre for Home Mechanical Ventilation, Division of Internal Medicine and Dermatology, **Dept of Biomedical Engineering, Technical Division, ${ }^{+}$Division of Obstetrics and Gynaecology, and ${ }^{++}$Dept of Pulmonary Diseases, Heart Lung Institute, University Hospital Utrecht, Utrecht, The Netherlands.

Correspondence: M.J. Kampelmacher Centre for Home Mechanical Ventilation, HP C02.410

University Hospital Utrecht

P.O. Box 85500

3508 GA Utrecht

The Netherlands

Fax: 31302505440

Keywords: Liquid oxygen long-term oxygen therapy oxygen flow rate

Received: March 261997

Accepted after revision February 161998

This study was supported by research grant no. 5204 from the Catharijne Stichting
Since 1988 the liquid oxygen system has increasingly been used in the Netherlands as an oxygen source by patients using long-term oxygen therapy (LTOT). Irrespective of the type, the system consists of a large canister for stationary use and a small one for portable use. Compared to oxygen cylinders and the oxygen concentrator, the liquid oxygen system has several advantages such as its convenience for home use and the light weight and high capacity of the portable canister [1-3]. A benefit regularly mentioned by oxygen companies is the reliability of the system. Although technical malfunctioning does not seem to occur more frequently than with oxygen cylinders, there have been some reports on the inaccuracy of the delivered oxygen flow $[4,5]$. Furthermore, some of our patients had the impression that they received less oxygen at the same flow rate when they changed from oxygen cylinders to the liquid oxygen system. In two patients the portable canister even supplied oxygen for a much longer period than predicted. The oxygen flow rate delivered may be less than intended owing to the inaccuracy of the set flow rates or as a result of the outflow resistance caused by the humidifier, oxygen tubing, delivery device and oxygen conserving devices, especially since the maximum outlet pressure of the liquid oxygen system is only half of that of oxygen cylinders $(\sim 300 \mathrm{kPa})$ $[4,5]$.

The purpose of this study was, therefore, to investigate the accuracy of oxygen delivery by liquid oxygen canisters at different oxygen flow rates and levels of outflow resistance.

\section{Materials and methods}

Initially, 15 portable liquid oxygen canisters (Companion 1000) and one stationary device (Companion 31A) from one manufacturer (Puritan-Bennett, Lenexa, KS, USA) were investigated. While the portable canisters were being used by 15 patients, the stationary canister was in regular use in the Department of Pulmonary Diseases of the University Hospital, Utrecht, The Netherlands. Both the portable canisters and the stationary device were maintained by oxygen provider $\mathrm{A}$.

Next, three portable canisters (two Strollers 1.2; Caire, Burnsville, MN, USA; and one Freelox 1.2*-7; Taema, Antony, France), and three stationary devices (two Libera- 
tors L-30 from Caire and one Freelox R32 from Taema), were tested, which were obtained from and maintained by oxygen providers $\mathrm{B}, \mathrm{C}$ and $\mathrm{D}$.

Depending on the set flow rate, the manufacturers' stated flow accuracy specifications varied from 13-83\% at $21^{\circ} \mathrm{C}$, at an ambient pressure of $100 \mathrm{kPa}(747 \mathrm{mmHg})$ and an operating pressure range of $2.7-3.0 \mathrm{kPa}$. The portable canisters were refilled before each test and the stationary canister contained at least $75 \%$ of its maximum oxygen capacity when tested. All flow measurements were performed with a Timemeter RT 200 Calibration Analyser (Allied Healthcare Product Inc., St. Louis, MO, USA), which has a manufacturer's stated accuracy of $\pm 2 \%$ of reading from $0-5 \mathrm{~L} \cdot \mathrm{min}^{-1}$ and of $\pm 1 \%$ of reading from 5$180 \mathrm{~L} \cdot \mathrm{min}^{-1}$ at $21.1^{\circ} \mathrm{C}$. Before each test the Timemeter was allowed to warm up for $10 \mathrm{~min}$, followed by an electronic zero calibration. To correct for possible drift a second check was carried out immediately before each test.

First, the flow rates delivered by the 11 flow settings of each canister were measured. The change in flow rate in time was measured in a Companion 1000 canister only. Next, the flow rates of the Companion 31A canister were measured with and without a bubble humidifier (Bubbler H/O 600 mL; Professional Medical Products, Greenwood, SC, USA). The effect of outflow resistance on the delivered flow rate was calculated by an adjustable obstruction in the tubing connecting the canister and the Timemeter. Measurements were performed at set flow rates of 0.5, 2.5 and $5.0 \mathrm{~L} \cdot \mathrm{min}^{-1}$. The obstruction at each of these was adjusted to reach the desired flow rates. The oxygen outlet pressure was measured for each desired flow rate. Finally, to find the resistance level of the tubing (Unifit bubble oxygen hose; minimum inner diameter $3.3 \mathrm{~mm}$ ) and oxygen delivery devices, air was delivered by a pressure-compensated rotameter (Hoek Loos, Amsterdam, The Netherlands) connected to an air wall source.

\section{Statistical analysis}

Data were analysed by using the SPSS/PC+ program (SPSS Inc., Chicago, IL, USA). Continuous variables are expressed as mean \pm SD. Linear regression and correlation coefficients were computed between measured and set flow rates. A paired t-test was applied for the comparison of oxygen flow rates of the stationary canister with and without a humidifier. Analysis of variance (ANOVA) was used to compare the mean oxygen outlet pressures of the 18 portable canisters when an obstruction had caused a $50 \%$ reduction in the set flow rate of $2.5 \mathrm{~L} \cdot \mathrm{min}^{-1}$. Twosided tests were applied throughout and a p-value of $<0.05$ was considered significant.

\section{Results}

\section{Flow rate accuracy}

The measured and set flow rates of the portable canisters were strongly correlated $(r=0.99 ; y=-0.02+0.99 x)$ (fig. 1). However, when expressed as percentage of the set flow rate, the measured flow rate varied from 36-118\%, with the lowest values at flow rates $<1 \mathrm{~L} \cdot \mathrm{min}^{-1}$ (fig. 2). Of the 198 flow rates measured $39(20 \%)$ were $>10 \%$ below and

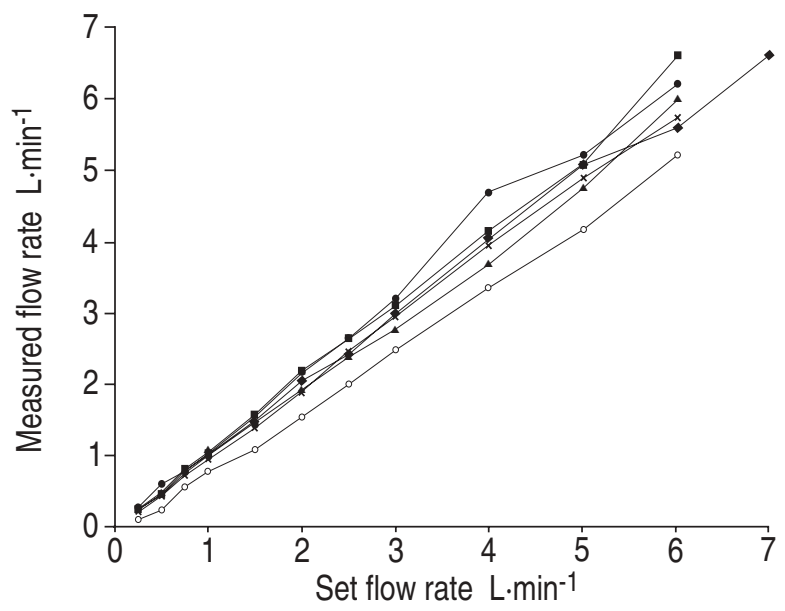

Fig. 1. - Comparison of the measured and set oxygen flow rates of 18 portable liquid oxygen canisters (three different types) from four oxygen providers. : Freelox; : Stroller B; $\wedge$ : Stroller C; o : Companion, minimum; $\mathbf{x}$ : Companion, mean; $\bullet$ : Companion, maximum.

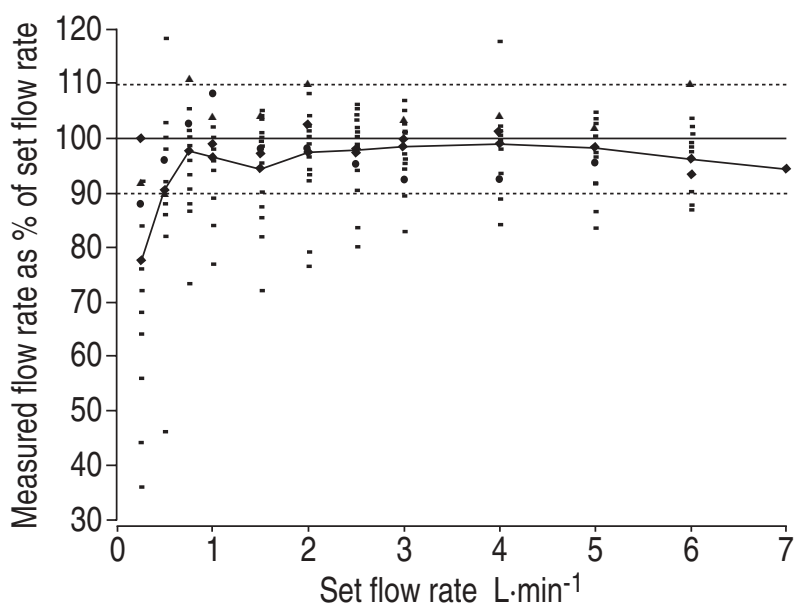

Fig. 2. - Comparison of the measured oxygen flow rate, expressed as percentage of the set flow rate, and the set flow rate of the 18 portable liquid oxygen canisters. - : Companion; $\bullet$ : Freelox; $\wedge$ : Stroller B; $\bullet$ Stroller C. Mean values are represented by the curve.

three $(2 \%)$ were $>10 \%$ above the set flow rate. Eleven $(7 \%)$ of the measured flow rates were $0.5-1.0 \mathrm{~L} \cdot \mathrm{min}^{-1}$ below the set flow rate, which was always $>2 \mathrm{~L} \cdot \mathrm{min}^{-1}$. In addition, at a set flow rate of $2 \mathrm{~L} \cdot \mathrm{min}^{-1}$ the measured flow rate remained constant until the canister was almost empty according to the contents indicator. Then, the flow rate fell to zero within $5 \mathrm{~min}$. The measured and set flow rates of the stationary canisters were also strongly correlated $(\mathrm{r}=$ $0.99 ; y=0.02+0.99 x$ ) (fig. 3), the former being $86-128 \%$ of the latter. Of the 44 flow rates measured, $13(30 \%)$ were $>10 \%$ below and one was $28 \%$ above the set flow rate. Interposition of a bubble humidifier did not cause any difference $(\mathrm{p}=0.22)$.

\section{Oxygen tubing}

An increase in oxygen outlet pressure resulting from progressive obstruction caused the set flow rate to decrease (fig. 4). It dropped by $10 \%$ or more if the obstruction had caused a mean pressure increase of $59 \pm 19 \mathrm{kPa}$ 


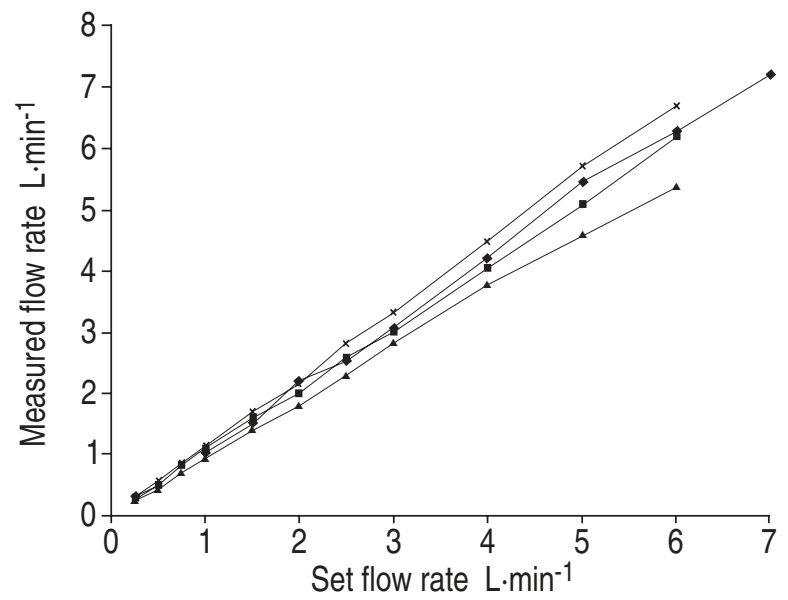

Fig. 3. - Comparison of the measured and set oxygen flow rates of four stationary liquid oxygen canisters (three different types) from four oxygen providers. $\bullet$ : Freelox; $\boldsymbol{\sim}$ : Liberator B; $\mathbf{\wedge}$ : Liberator C; $\mathbf{x}$ : Companion.

(range 9-100). In 16 devices it was impossible to measure the pressure that caused a $10 \%$ fall in the set flow rate because of internal leakage (three canisters) or inaccuracy of the flow setting (a deviation of at least $10 \%$ without an obstruction). A decline in the set flow rate by $10 \%$ due to a pressure increase of less than $25 \mathrm{kPa}$ occurred in three canisters (two portable) at a set flow rate of $0.5 \mathrm{~L} \cdot \mathrm{min}^{-1}$ only.

Although the location of the oxygen outlet pressureflow rate curve varied between the canisters, the pressure that had caused a $50 \%$ reduction in the set flow rate of 2.5 $\mathrm{L} \cdot \mathrm{min}^{-1}$ showed no difference between the portable canisters from different oxygen providers $(\mathrm{p}>0.05)$. At set flow rates of 2,6 and $12 \mathrm{~L} \cdot \mathrm{min}^{-1}$ the pressure in $10 \mathrm{~m}$ delivery tubing increased to $2.5,11.0$ and $26.6 \mathrm{KPa}$, respectively. Likewise, the set oxygen flow rates were hardly affected by the length of the tubing. At set flow rates of 0.5 and 6 $\mathrm{L} \cdot \mathrm{min}^{-1}$ on the stationary canister, the measured flow rates remained at $0.54 \mathrm{~L} \cdot \mathrm{min}^{-1}$ over $15 \mathrm{~m}$ of tubing and decreased from $6.12 \mathrm{~L} \cdot \mathrm{min}^{-1}$ at $5 \mathrm{~cm}$ to only $5.85 \mathrm{~L} \cdot \mathrm{min}^{-1}$ at $25 \mathrm{~m}$, respectively.

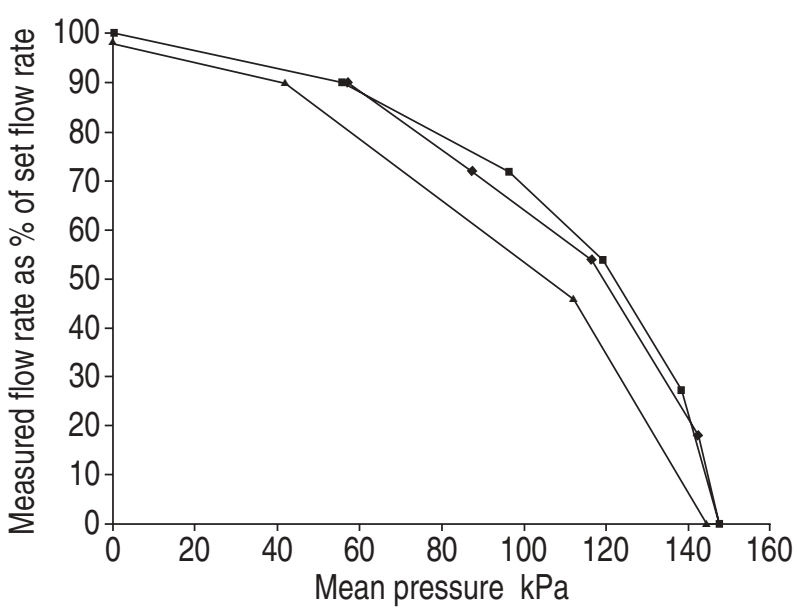

Fig. 4. - Mean change in measured oxygen flow rate, expressed as percentage of the set flow rate, due to variations in oxygen outlet pressure induced by a variable obstruction in four stationary and 18 portable liquid oxygen canisters. $\bullet 5.0 \mathrm{~L} \cdot \mathrm{min}^{-1} ; \boldsymbol{\bullet}: 2.5 \mathrm{~L} \cdot \mathrm{min}^{-1} ; \wedge: 0.5 \mathrm{~L} \cdot \mathrm{min}^{-1}$.

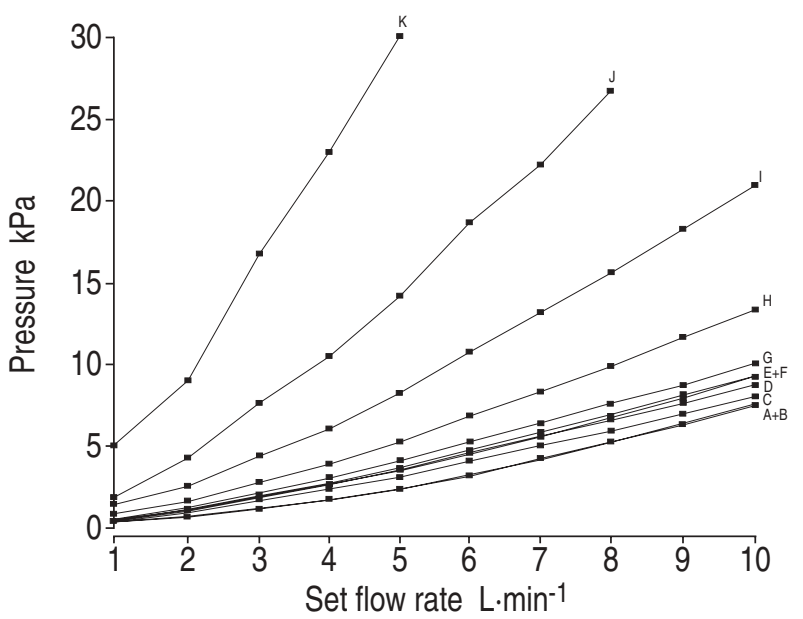

Fig. 5. - Pressures induced by several types of oxygen delivery devices at different flow rates of air. A: nasopharyngeal catheter, Ch.10; B: oxgyen catheter with foam pad, Ch.10; C, D, F, G, H, I: various types of adult nasal cannulae; E, J: paediatric nasal cannulae of different makes; K: low-flow nasal cannulae.

\section{Oxygen delivery device}

Depending on the oxygen delivery device and flow rate, pressures varied between $0.4-29 \mathrm{kPa}$ (fig. 5). The pressure increased with the magnitude of the set flow rate, regardless of the delivery device. The low-flow cannulae and one of the paediatric nasal cannulae caused higher pressures than either the nasopharyngeal catheter or the catheter with a foam pad. Finally, pressure differences between catheters from the same batch and between those of different batches were less than $2 \mathrm{kPa}$, even at a flow rate of 10 $\mathrm{L} \cdot \mathrm{min}^{-1}$.

\section{Discussion}

Since its introduction in 1988 the liquid oxygen system has gained much popularity among patients with LTOT in the Netherlands. However, along with the appreciation of the advantages of this oxygen source, doubts emerged about its accuracy, in particular with regard to the effect of the outflow resistance on oxygen flow rate. This study demonstrated that the accuracy of oxygen delivery by liquid oxygen canisters is principally determined by inaccuracy of the set flow rates.

Inaccuracy of the flow settings may be caused by dirt in the passages of the flow control valve or by variations in the system pressure, which is typically kept between the operating and relief pressure settings. Owing to leakage, the system pressure can be significantly lower than normal. The same problem occurs immediately after refilling, when incorrect filling techniques or source vessel pressures have been used. The canisters will return to normal operating pressure when the liquid oxygen warms to the appropriate saturation point. The system pressure can be higher than normal because of a malfunctioning safety valve, a high ambient temperature or a wrong position of the canister. The latter may decrease the relief venting and enlarge the evaporation surface. All of these factors may well explain the variations in delivered oxygen flow rate that were noticed by some patients. 
Compared to the inaccuracy of the flow settings, the effects of the humidifier, oxygen tubing and delivery device on oxygen delivery were relatively small. In general, the set flow rate decreased by only $10 \%$, or more if an obstruction had induced a pressure increase of at least 59 $\mathrm{kPa}$. Only at a set flow rate of $0.5 \mathrm{~L} \cdot \mathrm{min}^{-1}$ did the flow occasionally fall by $10 \%$, owing to a pressure increase of less than $25 \mathrm{kPa}$. Hence, provided the oxygen tubing and delivery device are not obstructed, this is unlikely to happen with appropriate oxygen equipment. A high outflow resistance could occur, however, if low-flow (paediatric) nasal cannulae are used with high flow rates due to the small internal diameter of the prongs. The oxygen flow rate delivered may decrease, in particular, if narrow oxygen tubing is used. With a minimum internal diameter of $3.3 \mathrm{~mm}$, the oxygen flow rate is hardly affected by the tubing length, even at high flow rates. By contrast, if the minimum inner diameter of the oxygen tubing is significantly smaller, as found in some newer types of silicone oxygen tubing, the oxygen flow rate delivered may decrease substantially. Finally, a malfunctioning oxygen conserving device may decrease the oxygen delivery to the patient substantially.

Although the differences between the measured and set flow rates were mostly small, they may have clinical significance, particularly in patients with chronic obstructive pulmonary disease (COPD) who only tolerate low flow rates. Even small changes in oxygen flow rate can be dangerous, especially during acute clinical exacerbations [6, 7]. If the oxygen flow rate is less than the set value, the patient may be exposed to serious hypoxaemia and its consequences. Conversely, a delivered flow rate that is much higher than the set value may result in hypercapnia and respiratory acidosis. Although regular pulse oximetry or, ideally, arterial blood gas testing can be helpful in detecting differences between set and observed flow rates, the best way to prevent inaccuracy is through monthly checks of the canisters by the oxygen provider. These checks can be fast, cheap and easy to perform, and they are more important than yearly maintenance since the canisters, unlike oxygen concentrators, do not have mech-anical parts or filters which need replacement.

Discrepancies between the set and delivered flow rates have been reported previously $[4,5]$. The results found by MASSEY et al. [4] were especially striking, particularly in the devices that were never inspected or serviced unless patients specifically complained about them. The canisters used in the present study were checked and serviced by the oxygen providers approximately once a year. Hence, although yearly maintenance did not preclude inaccuracy, it is likely to improve the functioning of the canisters.
The results of this study might be affected by the small number of canisters and the unbalanced diversity of types. However, given the fact that there were no major differences between the devices of different type or oxygen provider, there is no reason to believe that the results of the present study are not applicable to liquid oxygen canisters in general.

In conclusion, the present study demonstrates that the accuracy of oxygen delivery by liquid oxygen canisters depends more on the inaccuracy of the set flow rates than on the outflow resistance, even at high flow rates. Although the differences between the measured and set flow rates were mostly small, they may have clinical significance, particularly in patients with chronic obstructive pulmonary disease. To prevent inaccuracy, monthly checks of the canisters by the oxygen provider at the patient's home are more important than yearly maintenance.

Acknowledgements: The authors would like to thank F.E.I. Schaaf, director of Emdamed (Zoetermeer, The Netherlands), for kind supply of the oxygen delivery devices, and B.B.M. Boerkamp for her technical assistance in carrying out this project.

\section{References}

1. Siafakas NM, Vermeire P, Pride NB, et al. Optimal assessment and management of chronic obstructive pulmonary disease (COPD): a consensus statement of the European Respiratory Society (ERS). Eur Respir J 1995; 8: 1398-1420.

2. Lock SH, Blower G, Prynne M, Wedzicha JA. Comparison of liquid and gaseous oxygen for domiciliary portable use. Thorax 1992; 47: 98-100.

3. Petty TL. Home oxygen: a revolution in the care of advanced COPD. Med Clin North Am 1990; 74: 715-729.

4. Massey LW, Douglas Hussey J, Albert RK. Inaccurate oxygen delivery in some portable liquid oxygen devices. Am Rev Respir Dis 1988; 137: 204-205.

5. Mitlehner W, Würtemberger G. Tragbare Flussig- $\mathrm{O}_{2-}$ Quellen. Technische Eigenschaften und erste klinische Erfahrungen. Dtsch Med Wschr 1990; 115: 545-551.

6. Aubier M, Murciano D, Milic-Emili J, et al. Effects of the administration of oxygen on ventilation and blood gases in patients with chronic obstructive pulmonary disease during acute respiratory failure. Am Rev Respir Dis 1980; 122: 747-754.

7. Davies RJO, Hopkin JM. Nasal oxygen in exacerbations of ventilatory failure, an underappreciated risk. $\mathrm{Br}$ Med $J$ 1989; 299: 43-44. 